\title{
Multi-criteria Based Readiness Assessment for Developing Spatial Data Infiastruc tures in East Azerbaijan Province, Iran
}

GI_Forum 2018, Issue 2

Page: 322 - 333

Full Paper

Corresponding Author:

bakhtia r.feiziza deh@ta brizu.ac.ir

DOI: 10.1553 /giscience2018_02_s322

\author{
Da vood Behboudi, Parviz Moha madza de, Ba khtia r Feiziza deh and \\ Alirza Pooranvari \\ University of Tabriz, Iran
}

\begin{abstract}
Spatial Data Infrastructure (SDI) is known as a fundamental comprehensive approach of spatial data managing and sharing. Due to the complexity of establishing SDI, creating SDI has been considered as serious challenge, especially in developing countries. Successful and sustainable SDI can be developed when social, organizational and cultural issues are resolved in hamony with the technological ones. The framework of the present research is constructed on the basis of a survey and an SDI readiness model. Following a review of the research background, and taking into account the interaction of relevant indicators, criteria for establishing SDI were identified. After identification of the criteria, the data were collected through questionnaires and interviews with experts. 185 questionnaires were completed by 75 govemment-based departments, organizations, universities, and the private sector in East Azerbaijan province. The results were analysed and a readiness index was computed. The minimum chance of successfully establishing SDI was determined as being about $64.12 \%$, while the maximum rate was $89.48 \%$. The results are of great importance for analyzing the factors which may have signific ant impact on successful SDI development in East Azerbaijan province.
\end{abstract}

\section{Keywords:}

spatial data infrastructure, rea diness assessment, multic riteria approach, East Azerbaijan province, Iran

\section{Introduction}

Spatial Data Infrastructures (SDIs) form the basis of institutions' data-collection policies and arrangements that facilitate the availability of, and access to, spatial data. SDI provide a basis for spatial data discovery, evaluation and application for users and providers within all levels of government, the commercial sector, the non-profit sector and academia, and by citizens in general (Nebert, 2004). SDI is a concept developed for Spatial Data sharing between government and non-governmental organizations. The main goal of SDI implementation is to overcome the problem of duplication of data collection by organizations, which leads to wasting financial funds and time. SDIs have been developed for use at global, regional, national, state and local levels. 
Technically, SDIs involve a very intricate digital environment, such as a wide range of geospatial databases, networks, standards, metadata, institutional structures and technologies (Rajabifard, 2006). According to Williamson et al. (2003(, developing SDIs is critical, and the nature of SDIs is dynamic: partnerships, social systems, people, organizational structures and stakeholders' different views all influence the nature and characteristics of SDIs. Developing SDIs is strongly dependent on pre-existing infrastructures and technologies. It is also essential to understand some characteristics of these older infrastructures as well. Establishing SDIs and their complexity have also been considered as serious challenges. Successful and sustainable SDIs can be developed when social, organizational and cultural issues are resolved in harmony with the technological ones (Delgado Fernández et al., 2008). Due to the complexity of SDIs, a number of factors are involved for successful SDI development.

Recent studies worldwide have been carried out to assess the development of national SDIs (Crompvoets, 2006; Kok and van Loenen, 2004; Hyman et al., 2003). These studies have focused on countries implementing various components of SDI. A survey of national spatial data clearinghouses worldwide revealed that 67 countries had a published version of a clearinghouse on the Web, 13 had clearinghouses in the process of being published, and 113 had yet to implement a national geospatial data clearinghouse. With the majority of countries yet to initiate clearinghouse activities, one is inclined to ask what the obstacles are that are impeding efforts (Crompvoets, 2006; Delgado Fernández et al., 2008).

Due to the complex nature of establishing SDIs, the technical issues involved and the high costs especially in developing countries, it is advisable to assess the functionality and success chances of SDI development. The SDI-readiness concept refers to the degree to which a country is prepared for the delivery of its geographical information within a community (local, national, regional or global). It requires a variety of geospatial services with the widest connectivity to satisfy government, business and citizen geoinformation needs (Delgado Fernández et al., 2008). The SDI-readiness approach aims to identify the issues and challenges for establishing SDI. Having discussed the pros and cons of SDI, the main objective of this research is to apply the SDI-readiness model in East Azerbaijan Province, Iran.

\section{Study area and dataset}

The study area was East Azerbaijan Province (EAP), in northwestern Iran (Figure 1). This province is known as one of the country's main developed, industrial provinces (Feizizadeh and Blaschke, 2012; Karimzadeh et al. 2017; Shokati and Feizizadeh, 2018). It is a critical province in terms of the economy of the whole country, with about 3.7 million inhabitants, and around 80 national government-based organizations, departments and ministries. The resulting large number of spatial datasets requires an efficient SDI system for data gathering, sharing, updating and accessing. An SDI system is essential for sustainable development in $\mathrm{EAP}$, and there have been several attempts to establish a province-wide SDI. However, the lack of technical knowledge or of an existing network, and the existence over the last two decades of cultural and particularly financial issues have prevented establishing a successful SDI for the province. 


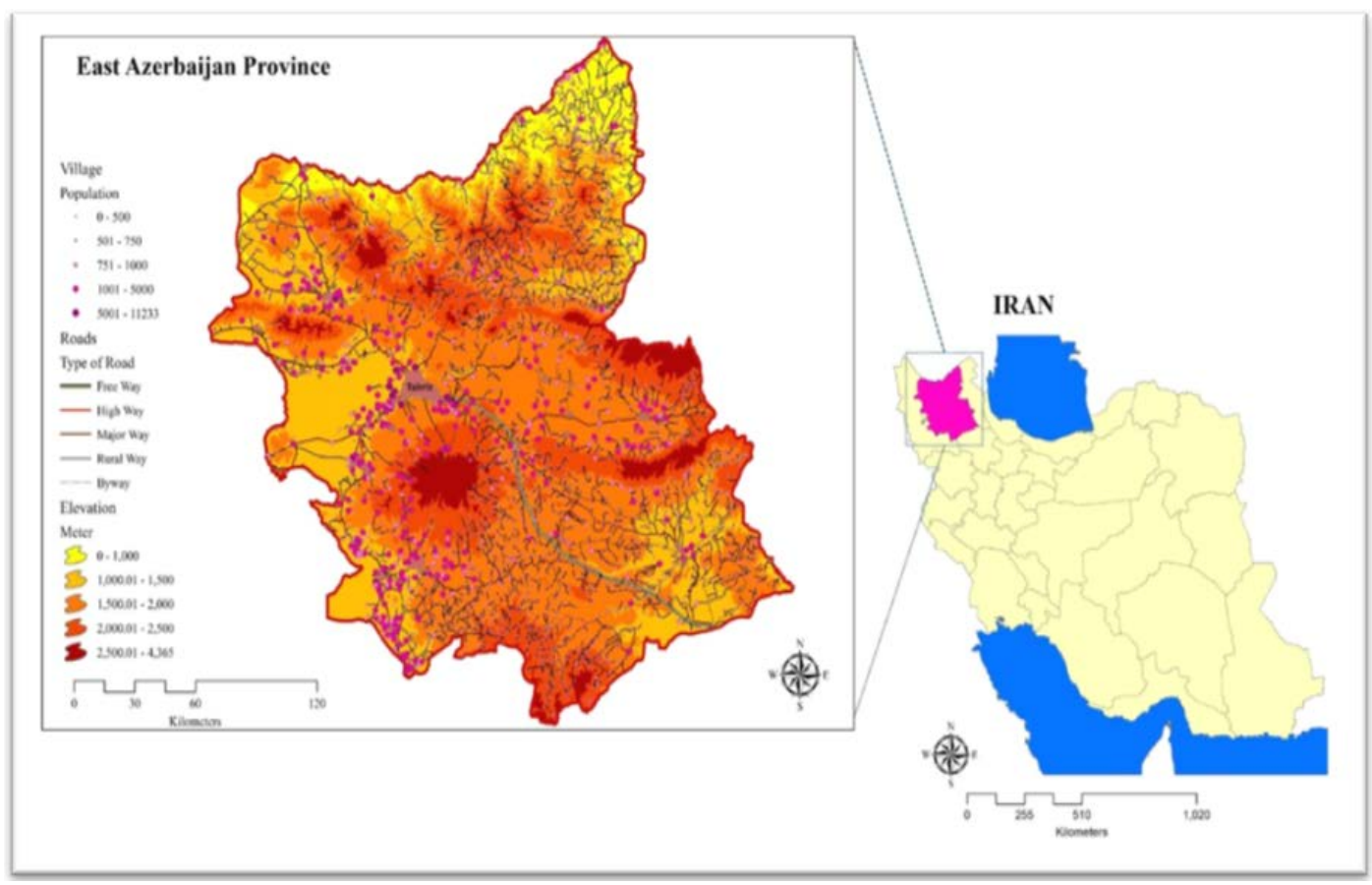

Figure 1: Location of the study a rea, EAP

\section{Methods}

\section{Selecting of SDI-readiness indexes}

To create an SDI-readiness index, it is necessary to identify a wide spectrum of factors that influence SDI development, to establish a hierarchy of priorities for these factors, and then to determine their incidence with respect to a National Spatial Data Infrastructure (NSDI) implementation (Delgado Ferandez, 2006). In order to assess SDI-readiness in EAP, we considered factors in multiple different readiness assessments. From a review of the literature and taking into account the interaction of relevant indictors for establishing SDI, the effective criteria were identified.

SDI readiness indexes integrate factors from several points of view. 11 main criteria and 41 sub-criteria are considered:

- Financial support (budget for GIS and spatial data projects, government sources, private sources, national geospatial initiatives)

- Motivation (motivation for using SDI and GIS in an organization's administrative processes)

- Organization (politicians' vision and support; institutional leadership; national legal agreements) 
- System understanding (clear understanding of SDI, GIS and spatial data, with support);

- People (educational level, SDI culture, GIS culture, individual leadership)

- Vision of spatial data (support for developing spatial data; support from managers, experts and users)

- professional skills (skills for working with such programs as Arc GIS, GPS, Auto CAD, SQL and databases, Web GIS, mobile GIS etc.)

- Program and plans (program and plans related to GIS and SDI)

- Technology (access to networks, web connectivity, technological infrastructure, geospatial software availability/in-house development)

- Data sharing (agreements for data sharing, Geo-server for data sharing, standards for data sharing)

- Data availability (quality of spatial data, providers' motivation, digital cartography availability, knowledge of standards)

After relevant criteria were identified, data were collected using questionnaires and interviews with experts working in government organizations, universities and the private sector. In total, 185 questionnaires were completed by 75 government-based departments, organizations, universities and private-sector companies in EAP. Figure 2 shows the decision tree of the main and sub-criteria.

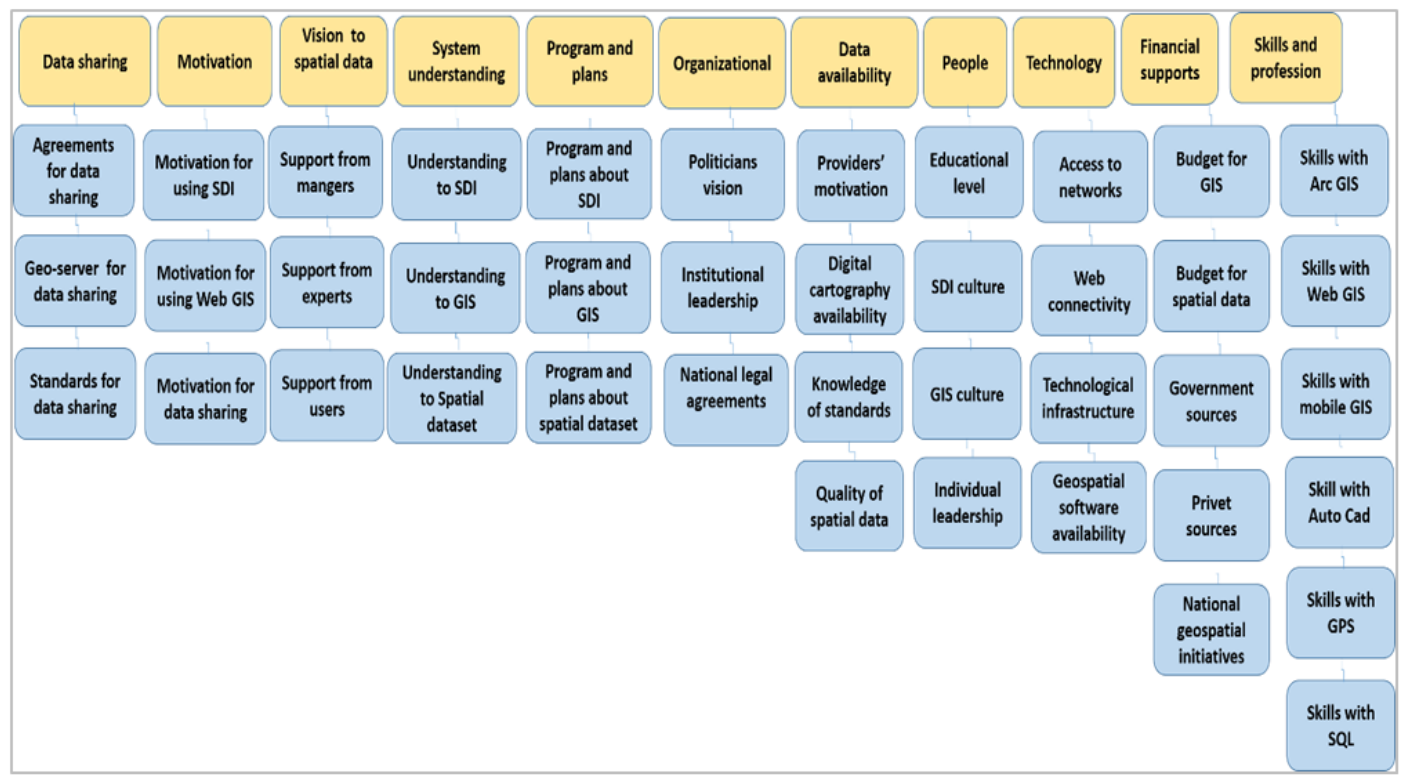

Figure 2: Decision tree matrix for the a nalytic al network process (ANP) for ranking ma in and sub-criteria 


\section{Multi-criteria-based readiness assessment}

Multi-criteria decision analysis (MCDA (is one of the most fundamental spatial decision support methods (Feizizadeh and Blaschke 2013; Feizizadeh et al. 2014; Abedi and Feizizadeh, 2017; Ghorbanzadeh et al. 2017; 2018). MCDA structures the parameters of decision problems and compares and ranks the criteria through a powerful set of techniques and algorithms (Feizizadeh and Blaschke 2014; Feizizadeh and Kienberger, 2017). Today, MCDA methods are applied to a wide range of sciences, and operations research in particular. Due to the multi-dimensional approach of SDI-readiness assessment, the analytical network process (ANP) method was applied to rank main criteria and sub-criteria. The ANP was introduced by Saaty (1996) as an effective method for criterion ranking and weighting based on a network approach (Chen and Yang, 2011). It was developed to reduce and minimize the uncertainty associated with criteria weighting when applying the Analytical Hierarchy Process (AHP). The ANP has been developed as an extensive and complementary technique of AHP and generally delivers more accurate results than traditional AHP (Ghorbanzadeh, 2017).

According to Saaty (1996), the ANP is a logical way to deal with dependence. Therefore, ANP can solve more complex problems than other MCDA models with interdependent relationships within a multi-criteria decision-making model. As a general rule, the ANP technique comprises three different stages (Zabihi et al., 2015):

- Selecting the most suitable alternative in cases of conflicting and interrelated factors (criteria) by modelling the decision problem

- Prioritizing the interrelated criteria according to a framework in order to evaluate the framework

- Assessing indirect influences of different criteria on each other and the relative importance of these influences throughout the network

Furthermore, since ANP is a mathematical process, it can systematically overcome all types of dependencies. In the first step, the technique creates a number of pairwise comparison matrices of the criteria. The relative significance value can be imposed through a scale of 1-9 (Saaty, 1996; Zabihi et al., 2015). The ANP represents a network that includes a number of small to big matrices of criteria and alternatives (both of them called elements), grouped into clusters. Links can relate the elements in the network to each other in any possible way. This network includes feedback and interdependence connections within and among clusters (Aragone's-Beltra'n et al., 2008).

Wij Component of Supermatrix

$$
W=\left[\begin{array}{cccc}
W_{i 1}{ }^{(j 1)} & W_{i 1}{ }^{(j 2)} & \ldots & W_{i 1}{ }^{\left(j n_{j}\right)} \\
W_{i 2}{ }^{(j 1)} & W_{i 2}{ }^{(j 2)} & \cdots & W_{i 2}{ }^{\left(j n_{j}\right)} \\
\vdots & \vdots & \vdots & \vdots \\
W_{i n_{i}}{ }^{(j 1)} & W_{i n_{i}}{ }^{(j 2)} & \cdots & W_{i n_{i}}{ }^{\left(j n_{j}\right)}
\end{array}\right]
$$


The priorities of each pairwise comparison matrix are calculated separately. However, the results of all individual pairwise comparison matrices are collected into an overall supermatrix (1) as parts of the columns in order to establish the final weights of the elements (Saaty, 2008).

Supermatrix W illustrates the influence of each element on other elements in the network system (Aragone's-Beltra'n et al., 2008). By applying the ANP technique, we aim to weight criteria (overall priorities). To do this requires calculating weights using a limited supermatrix and assigning weights based on the effectiveness of the criteria. Hence, the results of a limited matrix demonstrate the relative-importance weights for every factor. The limited matrix was obtained by calculating the square of each weighted supermatrix to capture the overall priorities of the factors. The general form of the limited supermatrix is described by Saaty (1996).

For this complex process, ANP offers more accurate modelling of complex problems such as spatial ones. In this approach, two subjects need to be solved for any reciprocal pairwise comparison matrix (RPCM: (a) consistency test, and (b) detection and modification of inconsistent element(s) (Ergu et al., 2014). Several studies on, and methods of, consistency evaluation exist, but consistency ratio (CR) is the most popular and practical for the pairwise comparison matrices in the ANP (Saaty, 1996; Zabihi et al., 2015). CR is expressed as:

$$
\mathrm{CR}=\frac{\lambda_{\max }-\mathrm{n}}{\mathrm{RI}(\mathrm{n}-1)}
$$

where $\lambda_{\max }$ is the maximum eigenvalue of matrix A, and RI (see Table 2) is the random index related to the number of criteria compared in the pairwise comparison matrix $((n)$ is order of matrix A) (Malczewski and Rinner, 2015). If $C R<0.10$, the matrix is deemed to have an acceptable level of consistency.

As already stated, the main objectives of this research are to develop a model for assessing SDI-readiness and to analyse difficulties for SDI development in EAP. For this, the ANP decision tree of main and sub-criteria was developed (see Figure 2). In order to calculate the criteria weights based on ANP, a questionnaire was designed to collect knowledge from a number of experts in the fields of GIS, use of databases and management. In total, 50 completed questionnaires were obtained. The estimated weights of the 11 criteria were considered by applying the ANP technique in super decision software. In the process, judgement matrices were completed. The Cluster Matrix and the final weighted, unweighted and limited matrix were also built, based on the relative importance of the criteria (see Table 1). In our study, the CR value for the pairwise matrix was calculated as 0.015 . 
Behboudi et al

Table 1: Decision tree matrix for the ANP method of ranking SDI-readiness criteria

\begin{tabular}{|c|c|c|c|c|c|c|c|c|c|c|c|}
\hline Criteria & 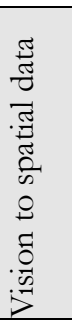 & 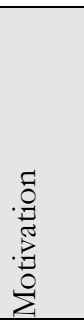 & 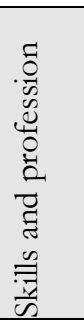 & 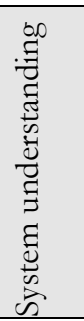 & 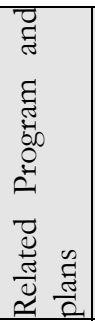 & 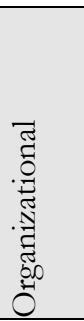 & 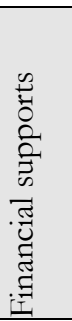 & $\begin{array}{l}\frac{0}{0} \\
0 \\
0 \\
0 \\
\tilde{0}\end{array}$ & 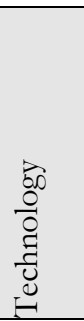 & 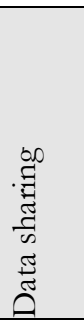 & 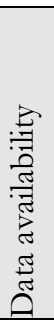 \\
\hline $\begin{array}{l}\text { Vision to } \\
\text { spatial data }\end{array}$ & 1 & 3 & 3 & 3 & 3 & 3 & 5 & 3 & 3 & 7 & 7 \\
\hline Motivation & 0.33 & 1 & 5 & 0.2 & 5 & 7 & 5 & 7 & 3 & 3 & 3 \\
\hline $\begin{array}{l}\text { Skills and } \\
\text { profession }\end{array}$ & 0.33 & 0.2 & 1 & 5 & 3 & 7 & 0.33 & 5 & 0.33 & 0.14 & 7 \\
\hline $\begin{array}{l}\text { System } \\
\text { understanding }\end{array}$ & 0.33 & 5 & 0.2 & 1 & 7 & 5 & 3 & 5 & 3 & 3 & 7 \\
\hline $\begin{array}{l}\text { Related } \\
\text { program and } \\
\text { plans }\end{array}$ & 0.33 & 0.2 & 0.33 & 0.14 & 1 & 7 & 7 & 7 & 3 & 9 & 9 \\
\hline Organizational & 0.33 & 0.14 & 0.14 & 0.2 & 0.14 & 1 & 7 & 5 & 3 & 7 & 9 \\
\hline $\begin{array}{l}\text { Financial } \\
\text { support }\end{array}$ & 0.2 & 0.2 & 3 & 0.33 & 0.14 & 0.14 & 1 & 7 & 5 & 9 & 9 \\
\hline People & 0.33 & 0.14 & 0.2 & 0.2 & 0.14 & 0.2 & 0.14 & 1 & 3 & 7 & 7 \\
\hline Technology & 0.33 & 0.33 & 3 & 0.33 & 0.33 & 0.33 & 0.2 & 0.33 & 1 & 9 & 9 \\
\hline Data sharing & 0.14 & 0.33 & 7.14 & 0.33 & 0.11 & 0.14 & 0.11 & 0.14 & 0.11 & 1 & 3 \\
\hline $\begin{array}{l}\text { Data } \\
\text { availability }\end{array}$ & 0.14 & 0.33 & 0.14 & 0.14 & 0.11 & 0.11 & 0.11 & 0.14 & 0.11 & 0.33 & 1 \\
\hline Total & 3.82 & 10.89 & 23.16 & 10.89 & 19.98 & 30.93 & 28.9 & 40.62 & 24.56 & 55.74 & 71 \\
\hline
\end{tabular}

\section{Motivation 14\%}

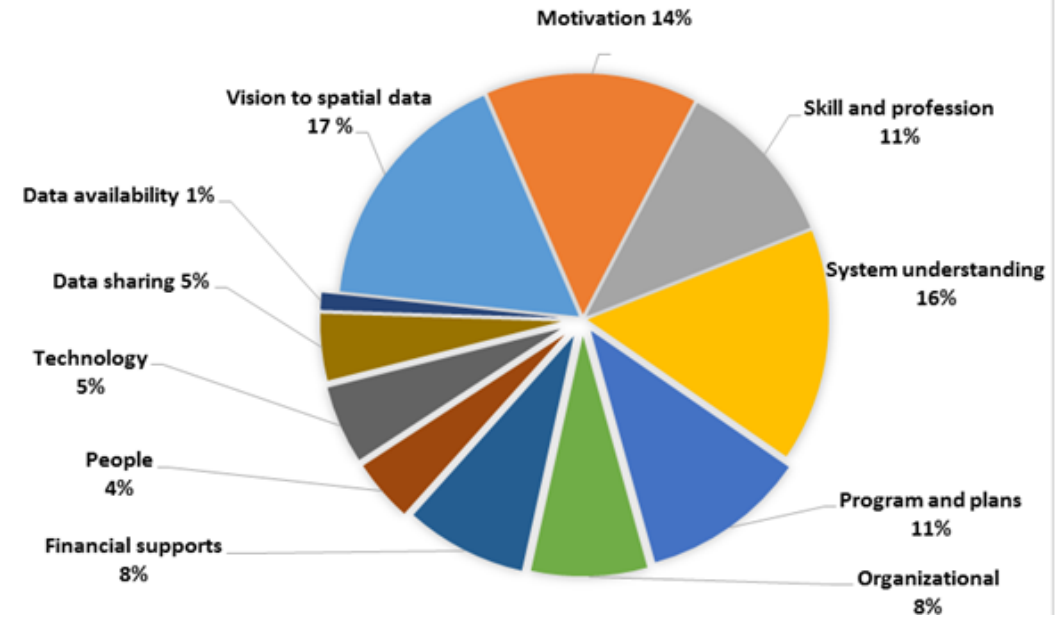

Figure 3: The weight of each criteria for SDI-rea diness 
Figure 3 shows the results of ANP-based criteria-ranking for SDI-readiness. Having correct understanding of spatial data is, with $17 \%$, identified as the most important criterion, closely followed by system understanding (16\%) and motivation (14\%). Skills and profession together with program and plan are identified next, with 11\%. Financial support and organization, both with $8 \%$, are also classified as important criteria. Drawing upon the results of MCDA evaluation, data sharing and technology (5\%), together with people $(4 \%)$ are also critical criteria for SDI readiness assessment. Finally, the ANP decision tree indicated data availability as the least important criterion (1\%).

\section{Applying a Likert scale}

A Likert scale was applied to compute the SDI-readiness index. The Likert scale is "A psychometric response scale primarily used in questionnaires to obtain participant's preferences or degree of agreement with a statement or set of statements" (Bertram, 2016: p. 1). Likert scales are a non-comparative scaling technique and are uni-dimensional (only measure a single trait). "Respondents are asked to indicate their level of agreement with a given statement by way of an ordinal scale" (ibid.). Likert-type data aim to measure attitude, providing a range of responses to a given question or statement. According to Dittrich, Francis, Hatzinger, and Katzenbeisser (2007), Likert scales are an effective tool in psychology and social surveys. In our case, there were five response categories, from strongly disagree to strongly agree. The original Likert scale employs a series of questions with five response alternatives (strongly approve, approve, undecided, disapprove, and strongly disapprove), although there are arguments in favour of scales with 7 or an even number of response categories (Jamieson, 2004). The responses from the series of questions can be combined to create an attitudinal measurement scale (Boone \& Boone, 2012; Prasad Subedi, 2016).

Our questionnaire had a total of 65 questions, based on the criteria. These covered: all information approaches and vision to spatial data; the skills and professions of GIS experts in each organization; system understanding related to GIS and SDI; GIS-related program and projects, and spatial databases; organizational skills; financial support in each organization; number of experts with backgrounds related to GIS and SDI; availability of technology (such as network, software, hardware etc.); data-sharing possibilities, and finally the quality of available data.

There were five possible Likert-style answers for each question, allowing respondents to indicate the real situation. For example, to evaluate financial support, the question and its answers were worded: "What are the official measures of financial support in your organization for GIS and SDI projects? Please choose one of the answers: weakly sufficient, sufficient, moderately sufficient, significant, and very strong". In total, 185 questionnaires were completed by 75 government-based departments, organizations, universities, and private-sector companies in EAP. The answers were analysed and the readiness index was computed. Based on this method, the minimum chance of successfully establishing SDI was determined as $64.12 \%$; the maximum rate was $89.48 \%$ (Figure 4). 


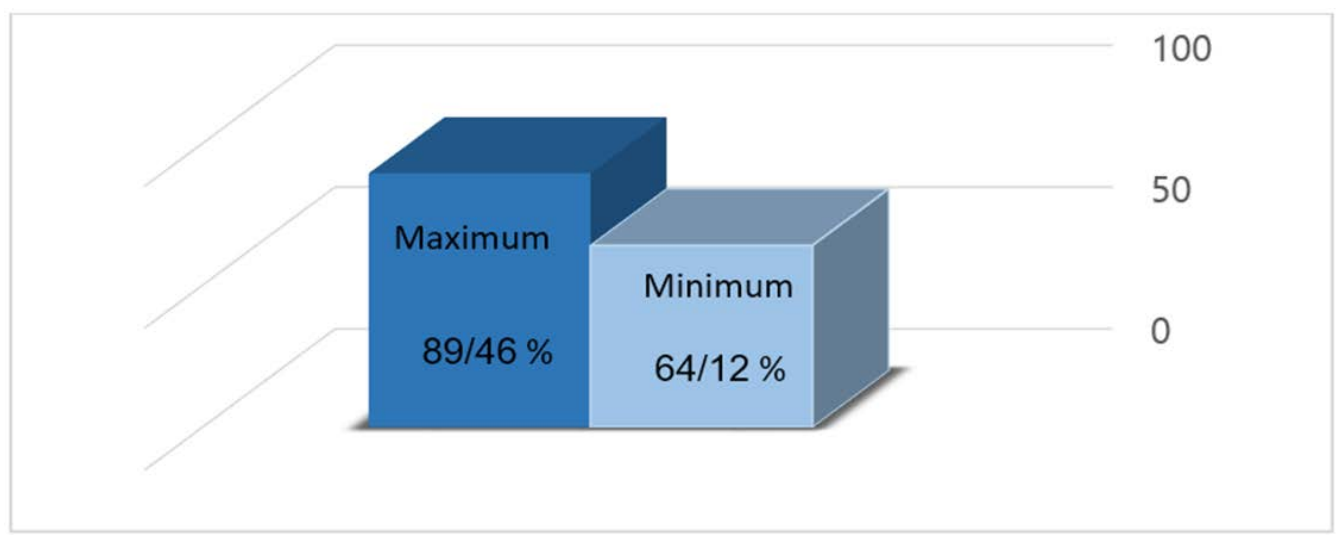

Figure 4: Results of Likert-sc a le questionna ire for EAP's SDI-rea diness

\section{Results and conclusion}

The research set out to analyse and determine the readiness index for developing SDI in East Azerbaijan province (EPA) Iran. According to the results, the province's readiness index is significant, while the minimum chance for successfully developing SDI was computed to be $64.12 \%$. We also aimed to identify the basic restrictions that might impact SDI development. The results of the model implementation together with those of the questionnaire indicated that there is a significant chance for successful development of EPA's SDI. This chance is higher than the readiness assessed for Iran's national SDI (NSDI), which Kalantari Oskouei et al. (2016) computed to be about $44 \%$. It should be noted that this figure of $44 \%$ is the overall average for developing SDIs in the 31 states of the whole country. Iran's NSDIreadiness report shows that some states such as EPA, Tehran and Isfahan represent the highest chance of SDI readiness. In southern Iran, meanwhile, in some states like Kerman, Charmahal Bakhtiarei, Boshehr, the SDI-readiness index is not significant.

GIS is being used widely and applied for many objectives in governmental departments in EPA, where most important organizations have also developed enterprise SDIs. These organizations include the national gas,, transport, and electricity companies, Agriculture and Natural Resources, the Municipality of Tabriz city, Water Resources and Management, which obviously has a significant impact for the successful development of state SDI. The department of remote sensing and GIS, University of Tabriz, has played a central role in GIS education and developing SDI in EPA, through workshops, summer/winter schools and participating in data-gathering. The department has also worked towards making the organizations and companies listed above both GIS- and SDI-ready.

The results of our survey indicated the main criteria currently limiting development of EAP's SDI as issues with enterprise and private-sector funding, individual leadership, standards, telecommunication infrastructure, institutional leadership, umbrella legal agreement, politicians' vision regarding SDI, metadata availability, and SDI culture/education. However, relevant technology such as web connectivity, digital geospatial data availability, human capital and geospatial software criteria emerged as being at a suitable level of development. 
Furthermore, it appears that non-technical factors (organizational, financial, human resources) were more important limiting factors in EAP's SDI development. These nontechnical aspects were also identified as critical issues in Iran's NSDI by Kalantari Oskouei et al. (2016).

According to Richter et al. (2010), people are one of the key factors in successfully establishing SDI. People as decision-makers drive SDI through their actions and behaviour, and in some cases even their individual personalities. They share geographic data, develop metadata standards, and formulate policies and monitoring criteria for SDI development. However, the SDI culture is still a challenge which might threaten SDI development. Results of this research also indicated that the lack of GIS and SDI knowledge especially at management level might be a critical point for successfully developing of EPA's SDI.

Due to the large number of stakeholders, data sharing, technology and network requirements, developing SDI is a very cost-effective technology. In every society, but especially in developing countries like Iran, there are also a significant number of threats affecting the development of SDI. SDI-readiness assessment leads to the identification of challenges and issues, and therefore helps to minimize their impacts on successfully developing SDI. By providing explicit guidelines for identifying challenges, our research, therefore, is of great importance for decision makers and authorities in EPA for the successful development of state SDI.

\section{Acknowledgement}

This paper was prepared from the results of a research project entitled "Needs Assessment and Requirements Analysis Report Spatial Data Infrastructure", supported by the Planning and Management Organization of East Azerbaijan Province, Iran.

\section{References}

Aragonés-Beltrán, P., Aznar, J., Ferrís-Oñate, J., García-Melón, M. (2008). Valuation of urban industrial land: An analytic network process approach. European Journal of Operational Research, 185(1), 322-339.

Abedi Gheshlaghi, H., Feizizadeh, B. (2017). An integrated approach of analytical network process and fuzzy based spatial decision making systems applied to landslide risk mapping, Journal of African Earth Sciences, 133, 15-24.

Bertram, D. (2016). Likert Scales. Retrieved July 18, 2016 from: http://my.ilstu.edu/ eostewa/497/Likert\%20topic-dane-likert.pdf.

Boone, H. N., Boone, D. A. (2012). Analysing Likert data. Journal of Extension, 50 (2). Retrieved from http://www.joe.org/joe/2012april/tt2p.shtml.

Chen, J., Yang, Y. (2011). A fuzzy ANP-based approach to evaluate region agricultural drought risk. Procedia Engineering, 23, 822-827.

Crompvoets, J. (2006). National Spatial Clearinghouses worldwide development and impact, $\mathrm{PhD}$ thesis, Wageningen University, The Netherlands. 


\section{Behboudi et al}

Dittrich, R., Francis, B., Hatzinger R. Katzenbeisser, W. (2007). A paired comparison approach for the analysis of sets of Likert-scale responses. Statistical Modelling 7 (1), 3 - 28. doi: $10.1177 / 1471082 X 0600700102$.

Drobne, S., Lisec, A. (2009). Multi-attribute decision analysis in GIS: weighted linear combination and ordered weighted averaging. Informatica, 33, 459-474.

Delgado Fernandez, T., Fernandez, M. D., \& Andrade, R. E. (2008). The Spatial Data Infrastructure Readiness model and its worldwide application. International Journal Crompvoets, A. Rajabifard, B. v. Loenen \& T. D. Fernandez (Eds.), A Multi-View Framework to Assess Spatial Data Infrastructures (pp. 117-134). Melbourne: Space for Geo-Information, Wageningen University.

Ergu, D., Kou, G., Shi, Y., Shi, Y. (2014). Analytic network process in risk assessment and decision analysis. Computers \& Operations Research, 42, 58-74.

Feizizadeh, B., Blaschke, T. (2014). An uncertainty and sensitivity analysis approach for GIS-based multicriteria landslide susceptibility mapping. International Journal of Geographical Information Science, 28(3), 610-638.

Feizizadeh, B., Blaschke, T. (2013). GIS-multicriteria decision analysis for landslide susceptibility mapping: comparing three methods for the Urmia lake basin, Iran. Natural Hazards, 65(3), 21052128.

Feizizadeh, B., Roodposhti, M.S., Jankowski, P. \& Blaschke, T. (2014). A GIS-based extended fuzzy multi-criteria evaluation for landslide susceptibility mapping. Computers \& geosciences. 2014 Dec 31; 73:208-21.

Feizizadeh, B. \& Kienberger, S. (2017). Spatially explicit sensitivity and uncertainty analysis for multicriteria-based vulnerability assessment, Journal of Environmental Planning and Management, 60(11). 2013-2035.

Feizizadeh, B., Blaschke, T. (2012). Land suitability analysis for Tabriz County, Iran: a multi-criteria evaluation approach using GIS, Journal of Environmental Planning and Management, _56, 1.23.

Ghorbanzadeh, O., Feizizadeh., B, Blaschke. (2018). An interval matrix method used to optimize the decision matrix in AHP techniques for GIS-based multiple criteria analysis, Journal of Environmental Earth Sciences, 77 (16), 584.

Ghorbanzadeh, O., Feizizadeh., B, Blaschke. (2017). Multi-criteria risk evaluation by integrating an analytical network process approach into GIS-based sensitivity and uncertainty analyses, Geomatics, Natural Hazards and Risk, 9 (1)127-151.

Jamieson, S. (2004), Likert scales: How to (ab) use them. Medical Education, 38, 1212 -1218.

Kalantari Oskouei, A., Modiri, M., Alesheikh., A.A., Hosnavi, R. (2016). Assessing national Spatial Data Infrastructure of Iran based on SDI readiness model, Journal Scientific-Research Quarterly of Geographical Data, 25 (99), 43-57.

Hyman, G., Perea, C., Rey, D. \& K. Lance. (2003). Survey of the Development of National Spatial Data Infrastructures in Latin America and the Caribbean, Proceedings of ESRI User's Conference, July 2003, San Diego, CA.

Kok, B., \& B. van Loenen. (2005). How to assess the success of National Spatial Data Infrastructures? Computers, environment and urban systems, 19: 699 -717.

Karimzadeh, S., Feizizadeh, B. \& Matsuoka, M. (2017). From a GIS-based hybrid site condition map to an earthquake damage assessment in Iran: Methods and trends, International Journal of Disaster Risk Reduction, 22, 23-36.

Malczewski, J., Rinner, C. (2015). Multicriteria decision analysis in geographic information science. Berlin, Heidelberg: Springer.

Nebert D. D. (2004). Developing Spatial Data Infrastructures: the SDI cookbook. Global Spatial Data Infrastructure (GSDI) Association. Available at http://gsdiassociation.org/images/publications/ cookbooks/SDI_Cookbook_GSDI_2004_ver2.pdf.

Prasad Subedi, B. (2016), Using Likert Type Data in Social Science Research: Confusion, Issues and Challenges, International Journal of Contemporary Applied Sciences, 3(2), 36-49. 


\section{Behboudi et al}

Rajabifard, A. (2008). A Spatial Data Infrastructure for a Spatially Enables Government and Society", in Crompvoets, J. et al (Eds.): 11-22.

Richter,C., Miscione,G., Georgiadou, Y. (2010), Conceptualizing people in SDI literature: Implications for SDI research and development, International Journal of Spatial Data Infrastructures Research, 5, 286325.

Rajabifard, A., A. Binns, et al. (2006), The role of sub-national government and the private sector in future spatial data infrastructures, International Journal of Geographical Information Science, 20(7): 727741.

Saaty, T. L. (1996). The analytic network process. Pittsburgh: RWS Publications.

Shokati,B., Feizizadeh, B. (2018). Sensitivity and uncertainty analysis of agro-ecological modeling for saffron plant cultivation using GIS spatial decision-making methods, Journal of Environmental Planning and Management. doi.org/10.1080/09640568.2018.1427561.

Williamson, I. P., A. Rajabfard, and M-E. F. Feeney. (2003). Developing Spatial Data Infrastructures: From Concept to Reality, London and New York: Taylor \& Francis.

Zabihi, H., Ahmad, A., Vogeler, I., Said, M. N., Golmohammadi, M., Golein, B., Nilashi, M. (2015), Land suitability procedure for sustainable citrus planning using the application of the analytical network process approach and GIS. Computers and Electronics in Agriculture, 117, 114-126. 